\title{
Synthesis of PAF, an Antifungal Protein from $P$. chrysogenum, by Native Chemical Ligation: Native Disulfide Pattern and Fold Obtained upon Oxidative Refolding
}

\author{
Györgyi Váradi, ${ }^{*[a]}$ Gábor K. Tóth, ${ }^{[a]}$ Zoltán Kele, ${ }^{[a]}$ László Galgóczy, ${ }^{[b]}$ \\ Ádám Fizil, ${ }^{[c]}$ and Gyula Batta ${ }^{[c]}$
}

\begin{abstract}
The folding of disulfide proteins is of considerable interest because knowledge of this may influence our present understanding of protein folding. However, sometimes even the disulfide pattern cannot be unequivocally determined by the available experimental techniques. For example, the structures of a few small antifungal proteins (PAF, AFP) have been dis-
\end{abstract}

closed recently using NMR spectroscopy but with some ambiguity in the actual disulfide pattern. For this reason, we carried out the chemical synthesis of PAF. Probing different ap-

Keywords: antifungal agents NMR spectroscopy $\cdot$ peptides $\cdot$ protein folding $\cdot$ solid-phase synthesis proaches, the oxidative folding of the synthetic linear PAF yielded a folded protein that has identical structure and antifungal activity as the native PAF. In contrast, unfolded linear PAF was inactive, a result that may have implications concerning its redox state in the mode of action.

\section{Introduction}

The development of new antifungal drugs is urgent and challenging ${ }^{[1,2]}$ because hosts and invading fungi may have similar cellular, physiological, and metabolic characteristics. Consequently, novel antimycotics that target specific fungi selectively and without side effects are required. During the last two decades, a broad range of antimicrobial proteins (peptides, AMPs) from different organisms, ranging from bacteria to humans, have been isolated and characterized. The number of known AMPs rapidly increased to a value above 4000, and approximately 600 of them have antifungal activity. ${ }^{[3]}$ However, in spite of the numerous studies of homologous antifungal proteins, ${ }^{[4]}$ the striking differences in their mode of action have not yet been disclosed.

PAF, an antifungal protein from Penicillium chrysogenum, is a cysteine-rich, cationic 55-mer protein. ${ }^{[5,6]}$ It was previously observed that PAF can effectively inhibit the growth

[a] Dr. G. Váradi, Prof. G. K. Tóth, Dr. Z. Kele

Department of Medical Chemistry, University of Szeged

Dóm tér 8, Szeged, 6720 (Hungary)

Fax: (+36) 62-545971

E-mail: varadi.gyorgyi@med.u-szeged.hu toth.gabor@med.u-szeged.hu

[b] Dr. L. Galgóczy

Department of Microbiology, University of Szeged Közép fasor 52, Szeged, 6726 (Hungary)

[c] Á. Fizil, Prof. G. Batta

Department of Organic Chemistry, University of Debrecen Egyetem tér 1, Debrecen, 4010 (Hungary)

Supporting information for this article is available on the WWW under http://dx.doi.org/10.1002/chem.201301098. of numerous filamentous fungi causing membrane permeabilization, intracellular oxidative stress, and evoking programmed cell death through a G-protein signal-transduction pathway. ${ }^{[7]}$ PAF is harmless for mammals, as proven in our recent PET (positron emission tomography) experiments. ${ }^{[8]}$ Therefore, PAF is promising for the treatment of mycoses and fungal infections, especially against aspergillosis. The structure of PAF is stabilized by three disulfide bridges, which are essential for biological activity. ${ }^{[6]}$ Chemical synthesis is not only a straightforward and convincing verification of the disulfide-bond pattern, but also allows the production of unusual "mutants" that cannot be produced by heterologous expression.

The chemical synthesis peptides containing multiple disulfides in a regioselective manner is still a challenging task for peptide chemists, although recently many improvements were described in the literature. ${ }^{[9,10]}$ The strategies involve either directed oxidative folding from polythiol precursors or stepwise introduction of the desired disulfide bonds using orthogonal protecting groups for the cysteine thiols. ${ }^{[1,12]}$ Both strategies can be carried out in the liquid phase or, rarely, on solid phase. ${ }^{[13,14]}$ The oxidative folding of fully deprotected linear peptides is a commonly applied approach; however, generation of the desired disulfide-bond pattern through this approach is not always possible. ${ }^{[15]}$ Orthogonal protection is more efficient in these cases, but the applicability of the numerous thiol protecting groups for efficient regioselective protection schemes is still restricted.

Herein, we describe the first successful chemical synthesis of PAF. Many routinely applied synthetic methods failed in our hands in the preparation of this miniprotein. Stepwise solid-phase synthesis has not provided the full-length pep- 
tide with acceptable yield; native chemical ligation had to be applied instead. Another challenge was to form the natural disulfide-bridge pattern. In addition to structure verification and biological activity checks of the products, we discuss solutions for the unexpected problems in the synthetic work. $^{[16]}$

\section{Results and Discussion}

Disulfide bonds are essential for the folding of small proteins. Determination of the redox state of cysteine residues is straightforward by either mass spectrometry ${ }^{[17-20]}$ or NMR spectroscopy. ${ }^{[19,20]}$ However, identification of the disulfide (SS) pattern by enzymatic digestion followed by mass spectrometry may be difficult because of the extreme stability of some disulfide proteins, especially PAF. X-ray diffraction is difficult to apply to small proteins, because of crystallization problems. Earlier, NMR studies could not be used to fully disclose the SS pattern in the case of two homologous proteins PAF and AFP. This is because the $C \beta-C \beta$ distances between SS-linked cysteine residues obtained from the NOEconstrained structure calculations $\left(\mathrm{CYANA}^{[21,22]}\right)$ may allow different SS patterns in the congested hydrophobic core of the two proteins. Therefore, to allow concurrent patterns, the structure of $\mathrm{PAF}^{[6]}$ (pdb code: $2 \mathrm{kcn}$ ) was published without explicit disulfide bonds, as was the case for $\mathrm{AFP}^{[23]}$ (pdb code: 1afp). There are ongoing NMR studies using ${ }^{15} \mathrm{~N} /{ }^{13} \mathrm{C}$ labeled PAF, combined with molecular dynamics calculations, in an effort to prove the PAF disulfide pattern solely by NMR spectroscopy. Until now, the results were in accordance with the preferred abcabc pattern and gave a root mean square deviation (RMSD) for backbone atoms of $0.44 \pm 0.14 \AA$ for the final ensemble of NMR-constrained CYANA calculations; a separate structural paper is in preparation. In principle, the NMR approach ${ }^{[24]}$ is preferred for small proteins; however, NOE correlations between covalently linked Cys residues can hardly be measured because the rate of intraresidue geminal cross relaxation involving the Cys $\beta$-protons is much higher than that of inter-residue relaxation. ${ }^{[2]}$ Exact measurement of long-range NOE correlations with the aid of stereospecific deuterium labeling of Cys $\beta$-protons and deuterium labeling at other carbon atoms in ${ }^{13} \mathrm{C}$-labeled BPTI was proposed recently. ${ }^{[25]}$ Alternative NMR approaches involving the mutation of cysteine into selenocysteine residues (heterologous expression or chemical synthesis) have also been suggested. ${ }^{[26]}$ Still, the most straightforward and convincing verification of the SS pattern of a particular protein may be through direct chemical synthesis. In fact, only the combination of mass spectrometric and NMR analysis can prove unequivocally the preferred abcabc pattern in the case of both native and synthetic PAF (Figure 1). Furthermore, rearrangement of disulfide bonds in other synthetic ways can prevent the production of PAF with the correct fold. One concurrent (abbacc) pattern could be excluded on the basis of the physical properties of the wrong synthetic PAF. In the case of native PAF, the DI-

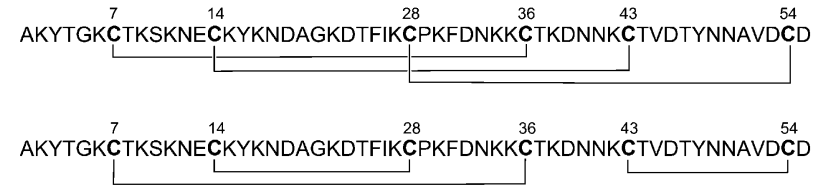

Figure 1. (Top) Supposed disulfide-bond connectivity of PAF: abcabc. (Bottom) The most probable concurrent pattern of PAF: abbacc.

SULFIND bioinformatics server predicted the abcabc pattern with the highest confidence ( 0.66 versus 0.35 for abcacb). However, in general, correct folding is not required for determining the SS pattern of linear peptides or their mutants with a lower number of possible disulfide bonds. ${ }^{[27,28]}$ The synthesis of proteins allows insertion of unusual residues; for example, the incorporation of selenocysteine residues allows conformational studies of disulfide bonds and that of fluorophenylalanine can facilitate in-cell NMR investigations.

The present study is important because verification of the PAF SS pattern could be used to confirm the pattern of homologous proteins such as AFP and NFAP. The spontaneous refolding of linear PAF, the biological activity of synthetic PAF, and the identical tertiary structures of native and synthetic PAF are interesting.

The following abbreviations are used throughout the paper: "Native PAF" refers to the naturally folded miniprotein isolated from a biological source; "linear PAF" refers to the reduced form of native PAF; "PAF-C3" refers to synthetic PAF having the natural connectivity of three disulfide bonds; "PAF-C1" and "PAF-C2" refer to synthetic peptides containing one and two disulfide bridges, respectively; "PAF-L" refers to the unfolded synthetic peptide bearing six sulfhydryl groups. Protecting groups are indicated in parentheses if they exist.

Chemical synthesis of unfolded PAF: The first attempt to prepare PAF was stepwise synthesis on solid phase. Being a 55 -mer protein, PAF is close to the limit in peptide length for preparation using the stepwise method. In accordance with this, an effective technique, microwave-assisted automatic Fmoc (fluorenylmethoxycarbonyl)-based synthesis using HBTU (2-(1H-benzotriazol-1-yl)-1,1,3,3-tetramethyluronium hexafluorophosphate)/HOBt (1-hydroxybenzotriazole) activation did not lead to the desired product. Boc (tert-butoxycarbonyl)-based chemistry was found to be more successful. However, the yield of purified PAF-L was only approximately $1.5 \%$ relative to the crude protein (see the Supporting Information, Figure S1). The length of the peptide together with the sequence might explain the failure of the syntheses. Furthermore, there are only 11 amino acids in the Fmoc protocol and 17 in the Boc protocol that can be used without side-chain protection in solid-phase synthesis. Therefore, the steric hindrance of larger protecting groups may decrease the efficacy of acylation.

The low yield of product obtained by using the stepwise synthesis prompted us to use native chemical ligation (NCL). NCL, introduced by Kent and co-workers, is a revo- 
lutionary method for the synthesis of relatively long peptides and proteins. ${ }^{[29,30]}$ This method combines the advantages of stepwise and convergent peptide synthesis. ${ }^{[31]}$ Stepwise solid-phase synthesis is usually limited to peptides of about 50 amino acids long owing to by-product formation and incomplete reactions. But the integration of stepwise solidphase synthesis with the benefits of a convergent strategy enables the preparation of full-size proteins. Native chemical ligation of a peptide $\alpha$-thioester ( $\mathrm{N}$-terminal fragment) and a Cys-peptide (C-terminal fragment) is based on a thiol-catalyzed thiol-thioester exchange and subsequent $\mathrm{S} \rightarrow \mathrm{N}$ acyl transfer (amide bond formation). PAF contains six cysteine residues at positions $7,14,28,36,43$, and 54 . PAF was cut into two fragments next to Cys-28. The C-terminal fragment $\left(\mathrm{P}_{28-55}\right)$, which includes Cys-28 at the $\mathrm{N}$-terminus, was synthesized according to standard solid-phase Boc chemistry. The average yield of the purified peptide was $11 \%$. The key building block in NCL is the thioester of the N-terminal fragment which, in most cases, is prepared with the use of 3mercaptopropanoic (3-MPA) acid by using Boc-based protocols. ${ }^{[32,33]}$ A generalized version of this method is the application of trityl-associated mercaptopropanoic-acid leucine (TAMPAL) resin. ${ }^{[34]}$ According to this method, a preloaded leucine resin is acylated with $S$-tritylmercaptopropanoic acid, the trityl group is removed by using TFA (trifluoroacetic acid), and the C-terminal amino acid is coupled to the $\mathrm{SH}$ group of cysteine, thus forming a thioester bond. Herein a modified method is discussed for the synthesis of the key component of NCL. Cys-SH resin, a universally applicable solid support, has been used for the Boc-based synthesis of peptide thioesters. When using the Cys-SH resin, the sulfhydryl group of a cysteine residue is used as thiol component of the thioester (Scheme 1). Using this simple and easy-to-use protocol, Fmoc-Cys(Trt)-OH was first coupled to MBHA (methylbenzhydrylamino) resin. Then, the Fmoc group was exchanged for an acetyl group through piperidine

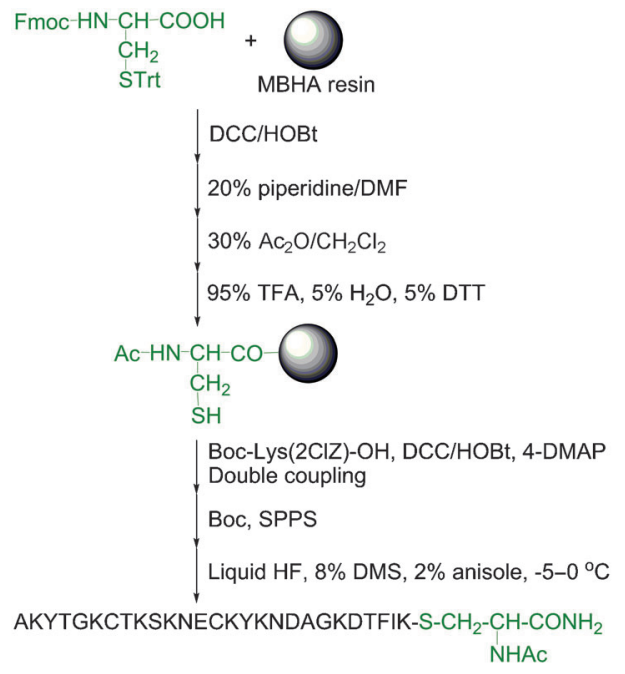

Scheme 1. Synthesis of peptide thioester P1-27 on the universally applicable Cys-SH resin. $2 \mathrm{ClZ}=2$-chlorobenzyloxycarbonyl, DMS $=$ dimethylsulfide, $\mathrm{DTT}=$ dithiothreitol, $\operatorname{Trt}=$ trityl. treatment and subsequent acetyl capping. Then, the trityl group was cleaved by using TFA and the C-terminal amino acid of the N-terminal fragment was coupled to the unblocked sulfhydryl group of cysteine. The same procedure as that used for the formation of normal oxoesters could be followed: double coupling with DCC (dicyclohexylcarbodiimide)/HOBt activation in the presence of a catalytic amount of 4-DMAP (4-dimethylaminopyridine). The remaining free sulfhydryl groups cannot be detected by color tests, but, according to a newly published method, the coupling efficiency can be determined by NMR spectroscopy. ${ }^{[35]}$ However, in the case of protected $\alpha$-amino acids that are routinely used in SPPS (solid-phase peptide synthesis), the quantitative assessment of the resin is unnecessary because the $\mathrm{SH}$ group is completely acylated under the reactions conditions given above. The peptide chain can be built up on the preloaded Cys-SH resin following standard Boc protocols. There is no need for special reagents or resins, this general and simple method being suitable for any C-terminal amino acid. $\mathrm{N}$-acetylcysteine, the leaving group of the thioester, is an easily treatable by-product of the ligation. The average yield of the purified peptide was $12 \%$.

After the solid-phase synthesis, native chemical ligation of the purified fragments was carried out in ammonium acetate buffer at $\mathrm{pH} 7.5$ in the presence of thiophenol. The strongly cationic fragments of PAF were soluble in the buffer without the need for adding guanidine hydrochloride. After the reaction went to completion $(4-5 \mathrm{~h})$, the mixture was purified by semipreparative HPLC so as to gain pure, unfolded PAF. Native chemical ligation provided a $48 \%$ average yield relative to the purified fragments.

The preparation of all of the differently protected peptides, that is, PAF where all Cys residues are protected with the same protecting group and PAF where the cysteine residues are protected selectively by using multiple protecting groups, was carried out according to the protocol discussed above. The synthesized peptides are summarized in Figure 2.

Comparing the two strategies, native chemical ligation resulted in about 3-4 times greater yield for the preparation of PAF relative to stepwise synthesis. Furthermore, the ease of purification of higher-quality crude peptide products also confirms the superiority of NCL.

Folding of PAF by selective protection of cysteine residues: Cysteine-rich peptides, in most cases, are synthesized by regioselective methods to ensure correct folding. Several issues had to be considered in the selection of protecting groups: compatibility of protecting groups with Boc chemistry and their stability against acids such as TFA and liquid HF. Those protecting groups that are cleavable by thiols could not be used because of the external thiol reagent in NCL.

On our first attempt, we applied the following set of protecting groups: Mbzl ( $p$-methylbenzyl), Fm (fluorenylmeth$\mathrm{yl}$ ), and Acm (acetamidomethyl). ${ }^{[36,37]}$ Mbzl is cleaved in parallel to the detachment of the peptide from the solid support, Fm is sensitive to base, and Acm can be removed by 

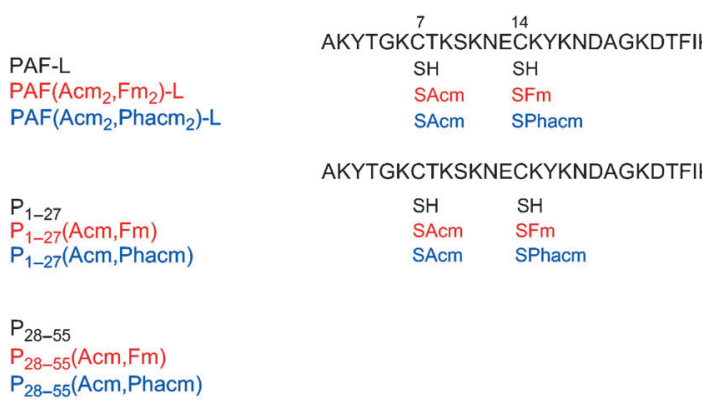

28
SH
SH
SH
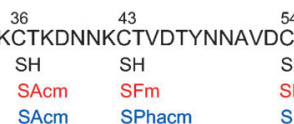

AKYTGKCTKSKNECKYKNDAGKDTFIK-S- $\mathrm{CH}_{2}-\mathrm{CH}-\mathrm{CONH}$

$\begin{array}{ll}\text { SH } & \text { SH } \\ \text { SAcm } & \text { SFm } \\ \text { SAcm } & \text { SPhacm }\end{array}$

NHAC

\begin{tabular}{|c|c|c|}
\hline & $17 \mathrm{sL}$ & STV \\
\hline $\mathrm{H}$ & $\mathrm{SH}$ & $\mathrm{SH}$ \\
\hline $\mathrm{H}$ & SAcm & SFm \\
\hline $\mathrm{SH}$ & $\mathrm{SAcm}$ & SPhacm \\
\hline
\end{tabular}

Figure 2. Sequences of the synthesized peptides. The short name PAF-L refers to the reduced form of fulllength PAF. P1-27 and P28-55 are the N- and C-terminal fragments, respectively, of PAF used for native chemical ligation. The protecting groups of cysteine residues are indicated in the names of the peptides. is advantageous because it extends the prospects of orthogonal protection in peptide chemistry. The formation of the first disulfide bond was carried out according to the procedure above. Because under the Acmdeprotection conditions, Phacm is also cleaved, Phacm had to be removed prior to Acm. To cleave the Phacm group, immobilized PGA from E. coli was applied. ${ }^{[40]}$ using iodine, thallium(III)-trifluoroacetate, silver(I), or mercury(II) salts. ${ }^{[38]}$ Following purification of the ligation product, oxidation of the formerly Mbzl-protected cysteine residues $\left(\mathrm{Cys}^{28,54}\right)$ was carried out with intense stirring of a $\mathrm{NH}_{4} \mathrm{OAc}$ buffer solution of the ligated product under an air atmosphere for 24 hours. The resulting solution was lyophilized three times to remove $\mathrm{NH}_{4} \mathrm{OAc}$. After that, $\mathrm{Cys}(\mathrm{Fm})$ residues $\left(\mathrm{Cys}^{14},{ }^{43}\right)$ were deprotected and oxidized by treatment with 10 or $20 \%(\mathrm{v} / \mathrm{v})$ piperidine in DMF (dimethylformamide) or ACN (acetonitrile) for 30 minutes, followed by overnight treatment with $2 \%(\mathrm{v} / \mathrm{v})$ piperidine in DMF or ACN buffered with $\mathrm{AcOH}$ to $\mathrm{pH} 8 .^{[13]}$ Surprisingly, rearrangement of the previously formed disulfide bridge has been observed by mass spectrometry analysis (see the Supporting Information, Table S1). We tried to use smaller concentrations of piperidine (10 or $15 \%)$ or DBU $(1,8-$ diazabicyclo[5.4.0]undec-7-ene) (1-5\% solution in ACN). Moreover, the exposure time of the disulfide bridge to basic conditions was decreased to only one hour by the use of $\mathrm{K}_{3}\left[\mathrm{Fe}(\mathrm{CN})_{6}\right]$ oxidation for 30 minutes after the removal of the Fm groups; however, none of these attempts led to the desired product. Owing to the failure of appropriate folding, we attempted to build in the other disulfide bridge ( $\left.\mathrm{Cys}^{7,36}\right)$ in the second stage. Iodine treatment successfully cleaved the Acm groups and oxidized the free $\mathrm{SH}$ groups to produce the second disulfide bridge. Mass spectrometry analysis revealed the correct SS pattern for the formed peptide, PAF$\left(\mathrm{Fm}_{2}\right)-\mathrm{C} 2$. As the last step of the synthesis, the Fm groups had to be removed with the use of a base. We hoped to avoid rearrangement if the structure was stabilized by two SS bridges under the conditions of basic treatment. Contrary to our expectations, unnatural disulfides bonds were formed (Figure 3). We concluded that PAF does not tolerate basic treatment; consequently, Fm could not be a protecting group of choice for the orthogonal protection of this miniprotein.

On our second attempt, we replaced the Fm group with the enzyme-cleavable $S$-phenylacetamidomethyl (Phacm) group ${ }^{[39]}$ Phacm has the same properties as Acm, thus, it is compatible with both Boc and Fmoc protocols. Moreover, Phacm can be selectively cleaved enzymatically by penicillin $\mathrm{G}$ amidase (PGA) (EC 3.5.1.11). The use of biocatalysts

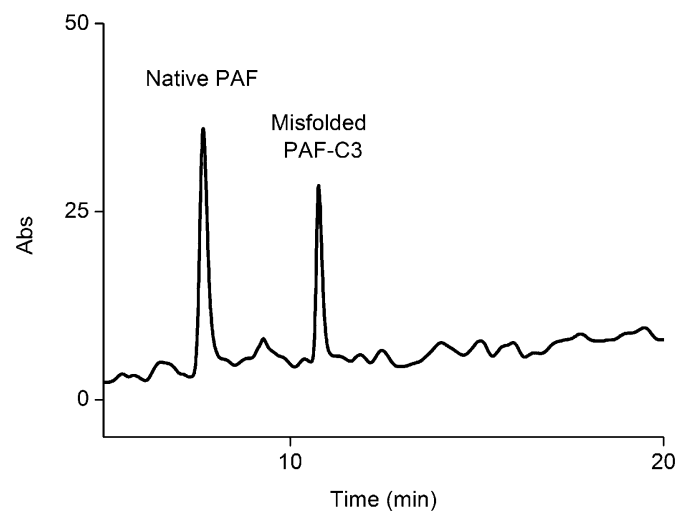

Figure 3. HPLC co-elution profile of PAF-C3 synthesized from PAF$\left(\mathrm{Acm}_{2}, \mathrm{Fm}_{2}\right)$-L and native PAF. Linear gradient: from 15 to $40 \%$ (solvent system $\mathrm{B}$ ) over $25 \mathrm{~min}$. Flow rate: $1.0 \mathrm{~mL} \mathrm{~min}^{-1}$.

Different conditions were tried for the enzymatic cleavage: temperatures between 36 and $38^{\circ} \mathrm{C}$, phosphate $(\mathrm{pH} 6.5$ and 7.5) and ammonium acetate ( $\mathrm{pH} 7.5)$ buffers, reaction times in the range $1-48 \mathrm{~h}$. However, the outcome was the same in all cases: the amount of $\operatorname{PAF}\left(\mathrm{Acm}_{2}, \mathrm{Phacm}_{2}\right)-\mathrm{C} 1 \mathrm{de}-$ creased continuously and finally the peptide disappeared from the reaction mixture. Our thinking was that nonspecific binding of the relatively large and highly cationic PAF to the carrier resin was responsible for the observation. To prove the idea, $\operatorname{PAF}\left(\mathrm{Acm}_{2}, \mathrm{Fm}_{2}\right)-\mathrm{C} 1$ was subjected to PGA treatment at $37^{\circ} \mathrm{C}$ in ammonium acetate buffer ( $\left.\mathrm{pH} 7.5\right)$. The reaction was followed by HPLC. In spite of the fact that $\operatorname{PAF}\left(\mathrm{Acm}_{2}, \mathrm{Fm}_{2}\right)-\mathrm{C} 1$ does not contain the substrate of $\mathrm{PGA}$, the peptide disappeared from the reaction mixture at about the same rate as $\operatorname{PAF}\left(\mathrm{Acm}_{2}, \mathrm{Phacm}_{2}\right)-\mathrm{C} 1$. We tried to liberate the peptide from the polymer using the following procedures: repeated washing with either phosphate buffer or $20 \%$ DMSO (dimethylsulfoxide) containing phosphate buffer, treatment with acetic acid/ water (9:1) mixture and sonication, dilution with $80 \%$ ethanol and sonication, washing with TFE (trifluoroethanol) and HFIP (hexafluoroisopropanol), treatment with $10 \mathrm{~mm}$ SDS (sodiumdodecylsulfate) solution. The filtrate was analyzed in each case, but the peptide could not been detected in any of the solutions. 
Since immobilized PGA did not work for PAF, we tried to circumvent the application of it by removing both the Phacm and Acm group pairs with the use of iodine. The use of iodine in acidic solution led to cleavage of the four protecting groups at the same time and formed two disulfide bridges simultaneously. HPLC analysis revealed different retention times for the product and natural PAF.

Folding of PAF by nonselective protection of cysteine residues: Different oxidation conditions were tested: a) the peptide was dissolved in $20 \%$ acetic acid and shaken with 3 equivalents of iodine for 1 hour; b) the peptide was dissolved in $20 \%$ acetic acid containing $6 \mathrm{~m} \mathrm{Gdn} \cdot \mathrm{HCl}$ and shaken with 3 equivalents of iodine for 1 hour; c) the peptide was dissolved in $0.1 \mathrm{M}$ ammonium acetate buffer having the $\mathrm{pH}$ of $7.5,8.5$, or 9.5 and subjected to air oxidation for 24 hours; d) the peptide was dissolved in $0.1 \mathrm{~m}$ glycine buffer, $\mathrm{pH} 10.5$, and subjected to air oxidation for 24 hours; e) the peptide was dissolved in $0.1 \mathrm{~m}$ ammonium acetate buffer and shaken with 30 equivalents of cross-linked ethoxylate acrylate resin (CLEAR-OX) support for 4 hours. ${ }^{[41]}$ The peptide concentration was $0.2 \mathrm{mg} \mathrm{mL}^{-1}$ in all cases. All the experiments showed a similar HPLC profile, and none of them resulted in the correctly folded peptide. Notably, the products of all attempts eluted from the reverse-phase column slower, that is, had a larger retention time than native PAF. Only one condition was found in which Cys residues of PAF paired correctly: addition of both an SH-group containing compound and an oxidizing agent to a solution of the peptide.

The idea was inspired by the almost quantitative rearrangement of the disulfide bridges of misfolded $\alpha$-conotoxin GI. ${ }^{[42]}$ In our most successful procedure, the peptide was dissolved in $0.1 \mathrm{~m}$ ammonium acetate buffer $(\mathrm{pH} 7.5)$ at a $0.2 \mathrm{mg} \mathrm{mL}^{-1}$ concentration and subjected to air oxidation with intensive stirring in the presence of a catalytic amount of cysteine $\left(0.2 \mathrm{mg} \mathrm{mL}^{-1}\right.$; Figure 4$)$. Oxidative folding with a glutathione-based redox buffer (1 mm GSH and $1 \mathrm{~mm}$ GSSG in $0.1 \mathrm{M}$ ammonium acetate buffer, $\mathrm{pH} 7.5$ ) provided natural pairing of cysteine residues with lower yield than the use of the cysteine- $\mathrm{O}_{2}$ system (see the Supporting Information, Figure S31 and S32).

Identification of disulfide bridges by mass spectrometry: Mass spectrometric methods for disulfide-bridge identification are based on chemical and enzymatic methods (according to the sequence of the protein or peptide), and produce a mixture of peptides containing only one disulfide bond. Fragments linked together through disulfide bridges are separated and analyzed by capillary reverse-phase HPLC coupled to the mass spectrometer. The fragments can be identified based on their unique masses and tandem mass spectrometric fragments. The success of the procedure usually depends on the reagents used for cleaving the peptide or protein at the half cystinyl residues. Based on the sequence of PAF, a mixture of trypsin and chymotrypsin was found to be a good choice. There is at least one cleavage site in this
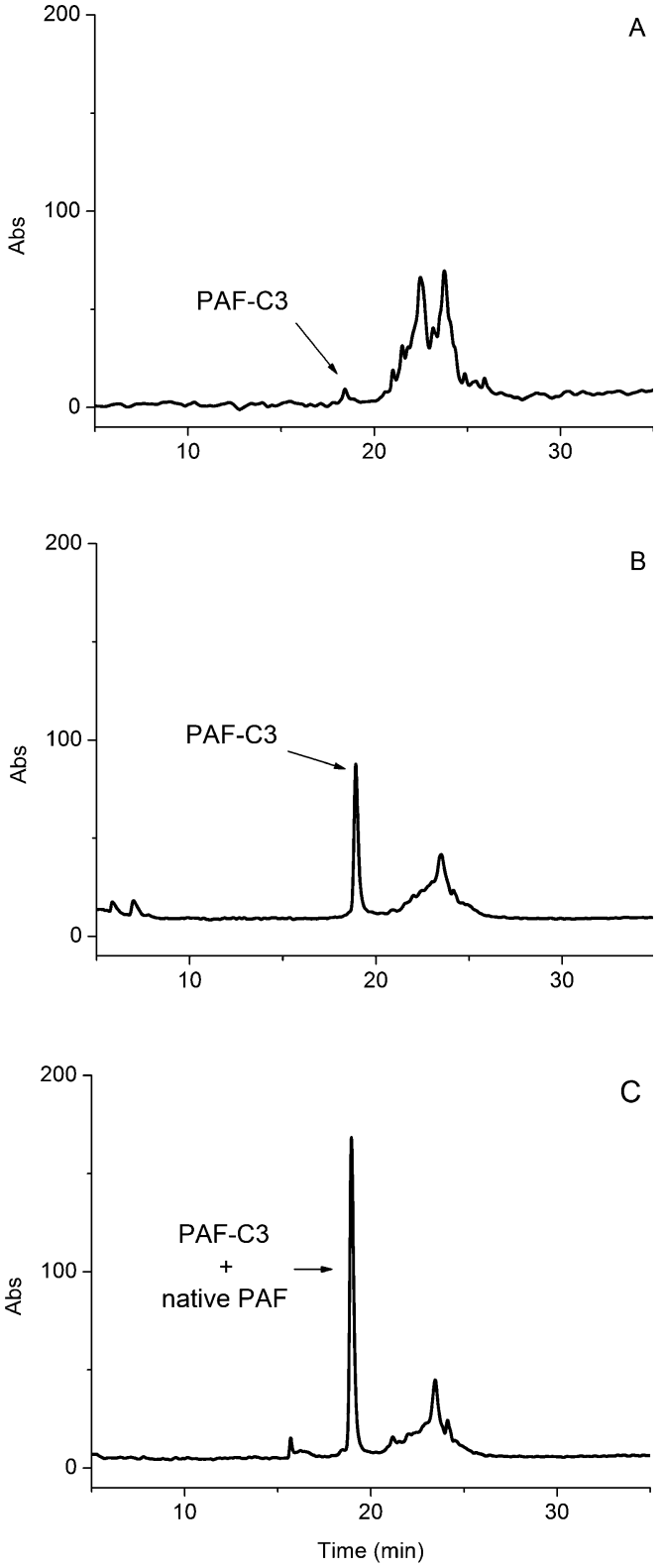

Figure 4. Oxidative folding of PAF-L in $0.1 \mathrm{~m} \mathrm{NH}_{4} \mathrm{OAc}$ buffer $(\mathrm{pH} 7.5)$ in the presence of catalytic amount of cysteine A) after $1 \mathrm{~h}$, and B) after $24 \mathrm{~h}$ reaction time. C) Co-injection of native PAF and the 24-h oxidativefolding reaction mixture. Linear gradient: from 5 to $40 \%$ (solvent system B) over $35 \mathrm{~min}$. Flow rate: $1.0 \mathrm{~mL} \mathrm{~min}^{-1}$.

enzyme cocktail (trypsin: at the N-terminus of $\mathrm{K}$ and $\mathrm{R}$; chymotrypsin at the $\mathrm{N}$-terminus of $\mathrm{F}, \mathrm{W}, \mathrm{Y}$ ) between every two neighboring cysteine residues, hence mass spectrometric analysis of PAF digestion can be used to find fragments linked together through disulfide bridges. To confirm that disulfide-linked fragments were derived from the examined peptide, the mass list was compared to that of the reduced form of the peptide: peaks belonged to peptide-derived SS linked fragments were not present mass spectra of the reduced sample. 
Mass spectrometric analysis of $\operatorname{PAF}\left(\mathrm{Acm}_{2}\right)-\mathrm{C} 2$ showed disulfide bridges between cysteine residues $14-28$ and 43-54. The most intense peaks and sequences of the digested sample are summarized in the Supporting Information, Table S1. The unnatural SS bond connectivity refers to the most probable concurrent pattern of PAF. Mass spectrometry analysis supports rearrangement of previously formed disulfide bonds under basic conditions.

Examination of native PAF and PAF-C3 successfully proved the supposed disulfide connectivity, thus, the presence of $\mathrm{S}-\mathrm{S}$ bonds between cysteine residues 7-36, 14-43, and 28-54. Ion chromatograms of the digested samples and disulfide-bonded peptide fragments are shown in Figure 5. The results are presented in more details in the Supporting Information, Tables S3 and S4. While more hits were found
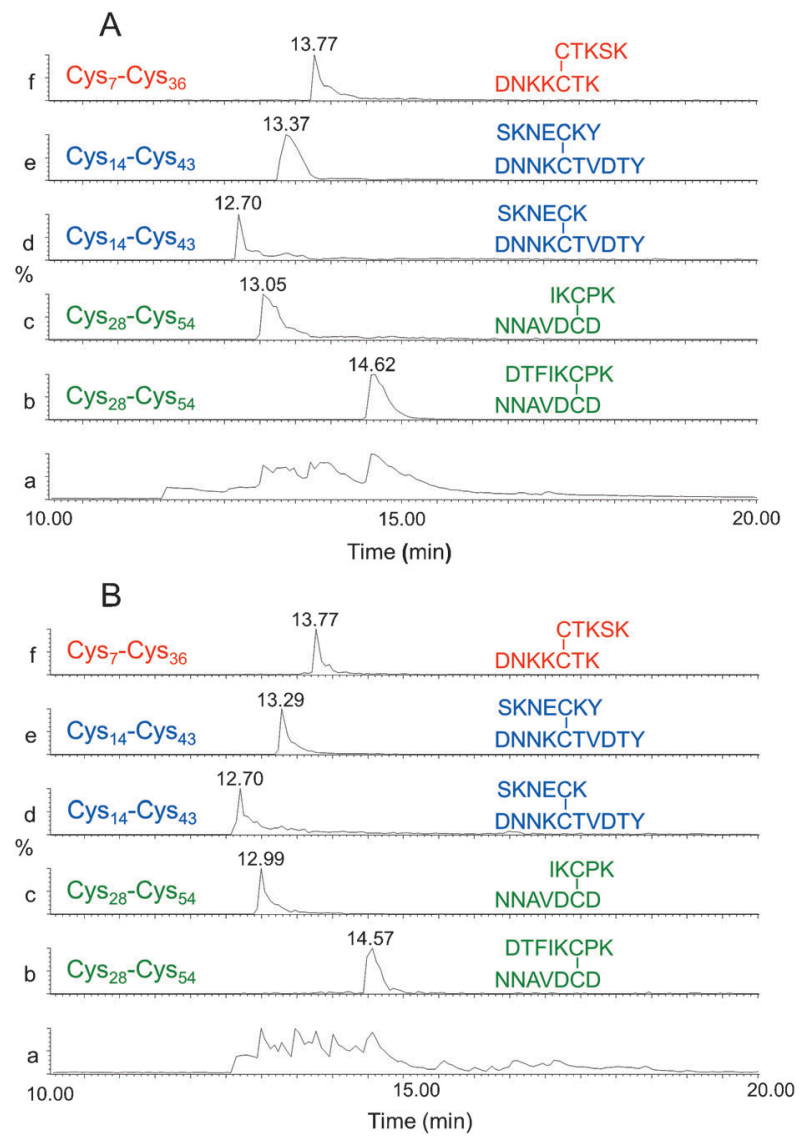

Figure 5. Identification of disulfide bridges A) in native PAF and B) in PAF-C3 by mass spectrometry. Base ion chromatogram of the enzyme-digested PAF (a) and different ion chromatograms (b-f) correspond to disulfide-bonded peptides found by analysis of mass lists are shown.

for the most intense peaks (peptide fragments containing a $\mathrm{S}-\mathrm{S}$ bond between cysteine residues $14-43$ and $28-54$ ), only one peptide confirmed the existence of the $\mathrm{Cys}^{7,36}$ bridge $(\mathrm{CTKSK}=\mathrm{DNKKCTK})$. This can be explained by the fact that the peptide resulting from complete enzymatic digestion $(\mathrm{CTK}=\mathrm{CTK})$ is too small and polar to be retained by the trapping column of the HPLC system.
The HPLC retention times of natural PAF and PAF-C3 were similar to each other. Both peptides showed high enzyme resistance, that is, even after 12 hours of proteolytic digestion, a significant amount of undigested peptide was found in the samples. Enzyme resistance can be the consequence of inaccessible cleavage sites. This high enzyme resistance was not shown by other synthetic PAF variants having unnatural disulfide-bridge patterns. Supposedly, misfolded PAF does not adopt a three-dimensional structure in which the cleavage sites are buried.

NMR investigations: Some time ago we investigated ${ }^{[6]}$ the structure, dynamics, and target-recognition aspects of the antifungal protein PAF (from Penicillium chrysogenum). Having a cationic nature owing to thirteen lysine residues and still exhibiting amphipathic character, it is an excellent antifungal protein model. Our structural analysis ${ }^{[6]}$ (pdb code: $2 \mathrm{kcn}$ ) by NMR spectroscopy showed that the tertiary structure of PAF is stabilized by three disulfide bonds. The present comparative studies on native, synthetic linear, and synthetic folded PAFs were carried out using ${ }^{1} \mathrm{H}$, ${ }^{1} \mathrm{H}$ NOESY and ${ }^{1} \mathrm{H}-{ }^{13} \mathrm{C}$ HSQC experiments. Linear PAF is surprisingly stable in solution (under Ar atmosphere) and is in an unfolded state, as shown by the ${ }^{1} \mathrm{H}$ and ${ }^{13} \mathrm{C}$ spectral pattern (see the Supporting Information, Figure S31). After approximately six weeks in solution, spontaneous refolding of PAF-L into native PAF becomes apparent (the doublets corresponding to Valine 45 appearing in the range $0.43-$ $0.46 \mathrm{ppm}$ being indicative); however folding stops at a very low concentration of folded protein. The well-folded structure of native PAF could be obtained by the oxidation as described above. NMR spectroscopy confirms the identity of native and synthetic folded PAF. The amide region of the ${ }^{1} \mathrm{H}$ NMR spectrum of synthetic folded PAF is the mirror image of that of the inverted spectrum of native PAF (Figure 6).

The ${ }^{13} \mathrm{C}-{ }^{1} \mathrm{H}$ correlation maps of the two proteins are virtually identical (Figure 7), data that further confirms the identity of the two proteins including the disulfide pattern and the $3 \mathrm{D}$ structure.

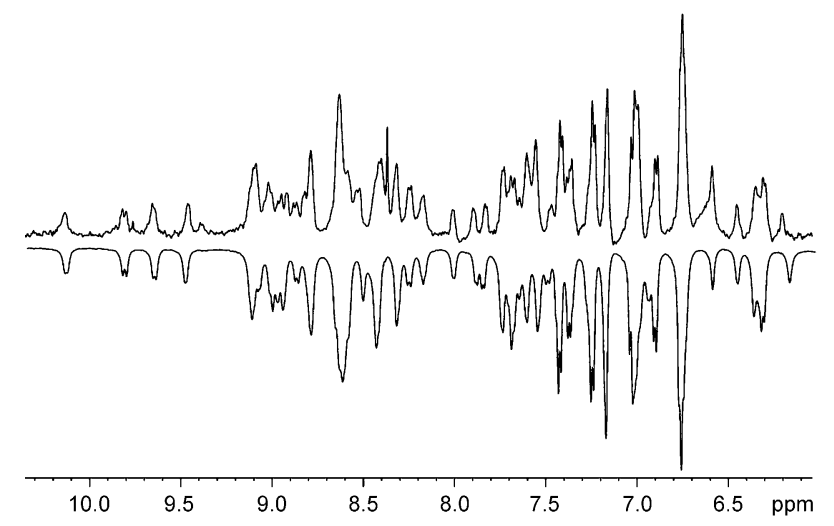

Figure 6. Amide-proton region of the ${ }^{1} \mathrm{H}$ NMR spectra of synthetic (top) and native (bottom) PAF. 
previously for PAF:[43] PAF-C3 also caused inhibition of spore germination and retardation of hyphae lengthening at a level depending on its applied concentration. The developed hyphae were very short, swollen, curved, and had multiple branches compared to the untreated control (see the Supporting Information, Figure S36).

\section{Conclusion}

Increasing interest in multiple-disulfide-containing polypeptides and small proteins has led to an extensive search for suitable routes for their synthesis. However, careful synthetic planning is required; for example, selective reduction of sulfur-based tert-butyl groups in the presence of disulfides can be problematic. ${ }^{[44]}$ According to our results, removal of Fm can lead to disulfide rearrangement and the application of the newly developed, enzyme-cleavable Phacm group is restricted owing to adsorption of larger peptides to the carrier resin.

The disulfide pattern of PAF was confirmed using different methods. First, homology (with AFP) and bioinformatics studies selects the abcabc pattern as being the most probable. Second, folding of linear PAF leads to a native PAF structure. Third, mass spectroscopy studies of synthetic products (non-native disulfide patterns) excluded some concurrent patterns and confirmed the native one. Fourth, ongoing extended NMR structural studies (to be published) are more consistent with the abcabc disulfide-bond pattern.

Herein, linear PAF did not exhibit an antimicrobial effect either under oxidative or reductive conditions. Previous studies demonstrated that the proper folding of the PAF is required for optimal activity and its highly conserved and positively charged lysine-rich surface region plays a central role in the toxicity of PAF towards target organisms. ${ }^{[6,45]}$ Based on our observations, the proper conformation of PAF was not obtained from its linear form under reductive conditions and the level of proper folding under oxidative conditions is too low for exertion of the antifungal effect.

Synthetic PAF and derivatives thereof are interesting subjects for further folding studies, for studies on the mode of action of antifungal proteins, and for potential pharmaceutical applications.

\section{Experimental Section}

growth inhibitory effect against all of the investigated fungal strains both in the presence of $5 \mathrm{~mm}$ GSH and the absence of it, thus indicating that this form of PAF is antifungally inactive (see the Supporting Information, Figure S34). The presence of $5 \mathrm{~mm}$ GSH did not have any influence on the antifungal activity of native PAF; the observed MIC values were the same as those measured in the absence of GSH (data not shown). The MIC data of our antifungal susceptibility tests indicate that the in vitro antifungal activity of PAF-C3 on filamentous fungi is at a similar level to that exerted by native PAF. The manifestation of the antifungal effect of PAF-C3 is practically identical to that observed
Peptide synthesis and purification: Peptides were prepared using solidphase synthesis. The stepwise synthesis of PAF was carried out either on a Liberty microwave peptide synthesizer (CEM Corporation, USA) by using Fmoc chemistry and HBTU/HOBt coupling protocols, or by manually using Boc chemistry and DCC/HOBt coupling protocols. PAF fragments for native chemical ligation were synthesized manually by using Boc chemistry. The C-terminal fragment $\left(\mathrm{P}_{28-55}\right)$ was prepared by using a standard DCC/HOBt coupling protocol. The N-terminal fragments $\left(\mathrm{P}_{1-27}\right)$ were synthesized as follows. First, Fmoc-Cys(Trt)-OH was attached to MBHA resin by using DCC/HOBt coupling. After that, the Fmoc group was cleaved by using $20 \%$ piperidine/DMF and the resulting free amino group was acetylated using $30 \%$ acetic anhydride $/ \mathrm{CH}_{2} \mathrm{Cl}_{2}$. Then the trityl 
group was cleaved by treatment with TFA containing $5 \%(\mathrm{v} / \mathrm{v}) \mathrm{H}_{2} \mathrm{O}$ and $5 \%(\mathrm{v} / \mathrm{v})$ DTT for a period of $2 \mathrm{~h}$. The C-terminal lysine was attached to the free sulfhydryl group of cysteine by applying DCC/HOBt double coupling in the presence of 4-DMAP. The synthesis of the rest of the peptide was carried using standard DCC/HOBt protocols. The crude peptides were purified by semipreparative RP-HPLC by using a solvent system of (A) $0.1 \%$ TFA and (B) $80 \%$ ACN, $0.1 \%$ TFA. The purity of the peptides was evaluated by analytical RP-HPLC and integrity of the products was verified by mass spectrometry by using a Finnigan TSQ 7000 tandem quadrupole mass spectrometer equipped with electrospray ion source. More detailed procedures are presented in the Supporting Information.

Native chemical ligation: The ligation of peptide fragments was performed in $0.1 \mathrm{M}$ ammonium acetate buffer ( $\mathrm{pH} 7.5)$ containing $3 \%$ thiophenol at $6-8 \mathrm{mg} \mathrm{mL}^{-1}$ peptide concentration at $25^{\circ} \mathrm{C}$. The reaction was monitored by analytical RP-HPLC. The ligation reached completion in $4-5 \mathrm{~h}$ in all cases. The precipitate was dissolved with the addition of 10 $15 \% \mathrm{ACN}$ and guanidine hydrochloride (6 $\mathrm{m}$ final concentration). The reaction mixture was filtered and purified by semipreparative RP-HPLC.

Oxidative folding of PAF: The linear peptide (PAF-L) was dissolved at a concentration of $0.2 \mathrm{mg} \mathrm{mL}^{-1}$. The conditions that resulted in misfolding of the protein are discussed in detail in the Results and Discussion Section. In the experiment that led to a natural disulfide bridge pattern, linear PAF was dissolved in $0.1 \mathrm{M} \mathrm{NH}_{4} \mathrm{OAc}$ buffer having the $\mathrm{pH}$ of 7.5 at a concentration of $0.2 \mathrm{mg} \mathrm{mL}^{-1}$. A catalytic amount of cysteine was added to the mixture and the resulting mixture was stirred intensively for $24 \mathrm{~h}$ at room temperature. Aliquots were taken at different times and checked by analytical HPLC. The mixture was then lyophilized three times and the final product was purified by semipreparative HPLC.

MS investigations: Samples were subjected to digestion with trypsin and chymotrypsin for $6 \mathrm{~h}$ at $37^{\circ} \mathrm{C}$. The digestion time was relatively short in order to keep rearrangement of disulfide bridges at a low level. The digested samples were analyzed on a Waters NanoAcquity UPLC system coupled with a Micromass Q-TOF premier mass spectrometer. 30-minlong gradients from 3 to $40 \%$ acetonitrile/water were applied on a Waters BEH130 C18 $75 \mu \mathrm{m} \times 250 \mathrm{~mm}$ column with $1.7 \mu \mathrm{m}$ particle size and $\mathrm{C} 18$ packing. The mass spectrometer was operated in MSE mode with lockmass correction (standard: Glu-1-Fibrinopeptide $\left[M+2 \mathrm{H}^{+}\right]$ $m / z=785.842$ ). All acquired data were processed and peak lists were generated by the WATERS Proteinlynx 2.3 software. The resulting peak lists were sorted according to their intensities and analyzed with disulfidebridge analyzer software. ${ }^{[46]}$

NMR spectroscopy: Typically, $1 \mathrm{mg}$ protein (native PAF, linear synthetic PAF-L, and folded synthetic PAF-C3) was dissolved in $275 \mu \mathrm{l}$ buffer (93:7 $\mathrm{H}_{2} \mathrm{O} / \mathrm{D}_{2} \mathrm{O}, 20 \mathrm{~mm} \mathrm{Na} \mathrm{PO}_{4}$, pH 6, $40 \mathrm{~mm} \mathrm{NaCl}, 0.04 \% \mathrm{NaN}_{3}$ ). The NMR spectra of protein solutions were measured in Shigemi NMR tubes at $298 \mathrm{~K}$. The folded synthetic and native PAF did not show any decomposition within a timeframe of one year; PAF-L started to spontaneously fold after a month. ${ }^{1} \mathrm{H}$ chemical-shift scales are referenced to sodium 2,2dimethyl-2-silapentane-5-sulfonate $(0 \mathrm{ppm})$ and heteronuclear shifts are referenced indirectly from the gyromagnetic ratios for ${ }^{15} \mathrm{~N}$ and ${ }^{13} \mathrm{C}$, thus giving $67.1 \mathrm{ppm}$ for the dioxane ${ }^{13} \mathrm{C}$ signal. The NMR spectra were recorded on an Avance II-500 (Bruker, Rheinstetten, Germany) spectrometer. Water signal suppression was achieved using the watergate5 sequence. ${ }^{[4]}$ Natural abundance ${ }^{13} \mathrm{C}-{ }^{1} \mathrm{H}$ HSQC spectra were acquired typically in overnight experiments. ${ }^{1} \mathrm{H}$ and ${ }^{13} \mathrm{C}$ hard-pulse length were in the 10-12/13-16 $\mu$ s range, respectively. Radiation-damping-suppressed 2D NOESY (130 ms mixing time) spectra were acquired in 2048.512 points and transformed to $4096 \cdot 2048$ points.

Bioinformatics: Some public bioinformatics tools (DISULFIND server) were applied for PAF disulfide pattern prediction. ${ }^{[48,49]}$

Antifungal activity assay: The minimal inhibitory concentrations (MIC) of native PAF, its synthetic form (PAF-C3), and PAF-L against PAF-sensitive Aspergillus nidulans (Fungal Genetic Stock Center, Kansas City, MO, USA; FGSC26), Aspergillus niger (Szeged Microbial Collection, University of Szeged, Szeged, Hungary; SzMC 601), and Trichoderma longibrachiatum (University of Alberta Microfungus Collection and Herbarium, Alberta, Canada; UAMH 7955) ${ }^{[50,51]}$ were determined by using a 96-well microtiter-plate bioassay and an agar-diffusion method using a low-cationic medium (LCM; $2 \mathrm{gL}^{-1}$ glucose, $0.1 \mathrm{gL}^{-1}$ yeast extract, $0.05 \mathrm{~g} \mathrm{~L}^{-1}$ peptone, $2 \mathrm{gL}^{-1}$ agar if necessary and supplemented with $2.5 \mu \mathrm{gL}^{-1}$ biotin in case of $A$. nidulans FGSC26).

In the 96-well microtiter-plate bioassays, $100-\mu \mathrm{L}$ solutions of PAF, PAF$\mathrm{C} 3$, or PAF in $50 \mathrm{~mm}$ Tris- $\mathrm{HCl} / \mathrm{OH}$ buffer $\mathrm{pH} 7.2$ was mixed with $100 \mu \mathrm{L}$ of conidial suspension $\left(10^{6}\right.$ conidia $\left./ \mathrm{mL}\right)$ prepared in double concentrated $\left(2 \times 10^{6}\right.$ condia per ML) LCM broth. In the cases of native PAF and PAF$\mathrm{L}$, peptides dissolved in the same buffer containing $5 \mathrm{~mm}$ of reduced $\mathrm{L}$ glutathione (GSH, Sigma-Aldrich) were also tested. GSH helps maintain the linear form of PAF-L. The final concentrations of the peptides were $50,25,12.5,6.25$, and $3.125 \mu \mathrm{g} \mathrm{mL}^{-1}$. The plates were incubated at $25^{\circ} \mathrm{C}$ and the optical densities were then measured at $620 \mathrm{~nm}$ with a microtiter-plate reader (ASYS Jupiter HD-ASYS Hitech) after 48 h. Fresh LCM broth was used as a background for the spectrophotometric calibration. To determinate the MIC values, optical densities of the untreated control cultures $(100 \mu \mathrm{L}$ buffer $+100 \mu \mathrm{L}$ conidia suspension) were referenced to $100 \%$ of growth, in each case. The MIC was defined as the lowest antifungal peptide concentration at which growth was not detected on the basis of the $\mathrm{OD}_{620}$ values as compared with the untreated control.

In the case of the agar diffusion technique, solid LCM was inoculated with $10^{6}$ conidia/mL and $100-\mu \mathrm{L}$ aliquots of serial peptide dilutions (50, $25,12.5$, and $6.25 \mu \mathrm{g} \mathrm{mL}^{-1}$ ), as used in microtiter-plate bioassay, were added into wells. The diameters of the inhibition zones were measured after incubation for $48 \mathrm{~h}$ at $25^{\circ} \mathrm{C}$. The MIC was defined as the lowest antifungal peptide concentration at which inhibition zone appeared around the well. Sterile buffer without protein was used as a negative control in this experiment.

Antifungal activity assays were repeated three times.

\section{Acknowledgements}

This work was supported by TÁMOP 4.2.1/8-09/1/KONV-2010-0005, 4.2.1./B-09/KONV-2010-0007 and TÁMOP 4.2.2 A-11/1/KONV-20120035 grants, by the Hungarian Scientific Research Fund OTKA CK 77515 and K 105459, and by the 83 öu 7 grant of the Austrian-Hungarian Action. L.G. holds a postdoctoral fellowship from the Hungarian Scientific Research Fund (OTKA; PD83355). We thank Prof. Florentine Marx (Innsbruck Medical University) for providing native PAF samples.

[1] M. Zasloff, Nature 2002, 415, 389-395.

[2] R. E. W. Hancock, H.-G. Sahl, Nat. Biotechnol. 2006, 24, 1551-1557.

[3] G. Wang, Antimicrobial Peptides: Discovery, Design and Novel Therapeutic Strategies, CAB International, London, 2010.

[4] L. T. Nguyen, P. H. S. Kwakman, D. I. Chan, Z. H. Liu, L. de Boer, S. A. J. Zaat, H. J. Vogel, Antimicrob. Agents Chemother. 2011, 55 , 2074-2083.

[5] F. Marx, H. Haas, M. Reindl, G. Stoffler, F. Lottspeich, B. Redl, Gene 1995, 167, 167-171

[6] G. Batta, T. Barna, Z. Gáspári, S. Sándor, K. E. Kövér, U. Binder, B. Sarg, L. Kaiserer, A. K. Chhillar, A. Eigentler, E. Leiter, N. Hegedüs, I. Pócsi, H. Lindner, F. Marx, FEBS J. 2009, 276, 2875-2890.

[7] F. Marx, U. Binder, E. Leiter, I. Pócsi, Cell. Mol. Life Sci. 2008, 65, 445-454.

[8] Z. Palicz, M. Fuzi, P. Szentesi, C. Hegedüs, E. Leiter, I. Pócsi, L. Csernoch, Acta Phys. Hung. 2010, 97, 468-468.

[9] A. M. Steiner, G. Bulaj, J. Pept. Sci. 2011, 17, 1-7.

[10] M. Góngora-Benítez, L. Mendive-Tapia, I. Ramos-Tomillero, A. C. Breman, J. Tulla-Puche, F. Albericio, Org. Lett. 2012, 14, 5472-5475.

11] H. Liu, M. A. Boudreau, J. Zheng, R. M. Whittal, P. Austin, C. D. Roskelley, M. Roberge, R. J. Andersen, J. C. Vederas, J. Am. Chem. Soc. 2010, 132, 1486-1487.

[12] G. K. Tóth, J. Pataricza, T. Janáky, M. Mák, M. Zarándi, J. G. Papp, B. Penke, Peptides 1995, 16, 1167-1172.

[13] J. A. Camarero, E. Giralt, D. Andreu, Tetrahedron Lett. 1995, 36 , $1137-1140$. 
[14] A. Cuthbertson, B. Indrevoll, Org. Lett. 2003, 5, 2955-2957.

[15] A. Isidro-Llobet, M. Álvarez, F. Albericio, Chem. Rev. 2009, 109, 2455-2504.

[16] G. Váradi, G. K. Tóth, Z. Kele, J. Pept. Sci. 2012, 18, S58-S200.

[17] J. J. Gorman, T. P. Wallis, J. J. Pitt, Mass Spectrom. Rev. 2002, 21, $183-216$.

[18] D. L. Smith, Z. Zhou, in Methods in Enzymology (Ed.: J. A. McCloskey), Academic Press, 1990, pp. 374-389.

[19] D. Sharma, K. Rajarathnam, J. Biomol. NMR 2000, 18, 165-171.

[20] O. A. Martin, M. E. Villegas, J. A. Vila, H. A. Scheraga, J. Biomol. NMR 2010, 46, 217-225.

[21] T. Herrmann, P. Güntert, K. Wüthrich, J. Biomol. NMR 2002, 24, $171-189$.

[22] T. Herrmann, P. Güntert, K. Wüthrich, J. Mol. Biol. 2002, 319, 209 227.

[23] R. Campos-Olivas, M. Bruix, J. Santoro, J. Lacadena, A. M. Delpozo, J. G. Gavilanes, M. Rico, Biochemistry 1995, 34, 3009-3021.

[24] L. Poppe, J. O. Hui, J. Ligutti, J. K. Murray, P. D. Schnier, Anal. Chem. 2012, 84, 262-266.

[25] M. Takeda, T. Terauchi, M. Kainosho, J. Biomol. NMR 2012, 52, 127-139.

[26] M. Mobli, A. D. de Araújo, L. K. Lambert, G. K. Pierens, M. J. Windley, G. M. Nicholson, P. F. Alewood, G. E. King, Angew. Chem. 2009, 121, 9476-9478; Angew. Chem. Int. Ed. 2009, 48, 9312-9314.

[27] R. Silvers, F. Sziegat, H. Tachibana, S.-i. Segawa, S. Whittaker, U. L. Günther, F. Gabel, J.-r Huang, M. Blackledge, J. Wirmer-Bartoschek, H. Schwalbe, J. Am. Chem. Soc. 2012, 134, 6846-6854.

[28] E. S. Collins, J. Wirmer, K. Hirai, H. Tachibana, S. Segawa, C. M. Dobson, H. Schwalbe, ChemBioChem 2005, 6, 1619-1627.

[29] P. E. Dawson, T. W. Muir, I. Clarklewis, S. B. H. Kent, Science 1994, 266, 776-779.

[30] P. E. Dawson, S. B. H. Kent, Ann. Rev. Biochem. 2000, 69, 923-960.

[31] S. B. H. Kent, Chem. Soc. Rev. 2009, 38, 338.

[32] H. Hojo, S. Aimoto, Bull. Chem. Soc. Jpn. 1991, 64, 111-117.

[33] S. Aimoto, Biopolymers 1999, 51, 247-265.

[34] T. M. Hackeng, J. H. Griffin, P. E. Dawson, Proc. Natl. Acad. Sci. USA 1999, 96, 10068-10073.
[35] D. Rentsch, C. Stähelin, M. Obkircher, R. Hany, M. Simeunovic, D Samson, G. Loidl, F. Dick, ACS Comb. Sci. 2012, 14, 613-620.

[36] M. Bodanszky, M. A. Bednarek, Int. J. Pept. Protein Res. 2009, 20, 434-437.

[37] D. Veber, J. Milkowski, S. Varga, R. Denkewalter, R. Hirschmann, J. Am. Chem. Soc. 1972, 94, 5456-5461.

[38] N. Fujii, A. Otaka, S. Funakoshi, K. Bessho, T. Watanabe, K. Akaji, H. Yajima, Chem. Pharm. Bull. 1987, 35, 2339-2347.

[39] M. Royo, J. Alsina, E. Giralt, U. Slomcyznska, F. Albericio, J. Chem. Soc. Perkin Trans. 1 1995, 1095.

[40] H. Xiang, G. Y. Xiang, Z. M. Lu, L. Guo, H. Eckstein, Amino Acids 2004, 27, 101-105.

[41] K. Darlak, D. Wiegandt Long, A. Czerwinski, M. Darlak, F. Valenzuela, A. F. Spatola, G. Barany, J. Peptide Res. 2004, 63, 303-312.

[42] I. Szabó, G. Schlosser, F. Hudecz, G. Mezo, Biopolymers 2007, 88, $20-28$.

[43] L. Kaiserer, C. Oberparleiter, R. Weiler-Gorz, W. Burgstaller, E. Leiter, F. Marx, Arch. Microbiol. 2003, 180, 204-210.

[44] P. A. Raj, K. J. Antonyraj, T. Karunakaran, Biochem. J. 2000, 347, 633.

[45] F. Marx, W. Salvenmoser, L. Kaiserer, S. Graessle, R. Weiler-Gorz, I. Zadra, C. Oberparleiter, Res. Microbiol. 2005, 156, 35-46.

[46] P. R. Baker, Clauser, Proteinprospector MSbridge.

[47] M. Liu, X. Mao, C. Ye, H. Huang, J. K. Nicholson, J. C. Lindon, J. Magn. Reson. 1998, 132, 125-129.

[48] B. Rost, G. Yachdav, J. Liu, Nucleic Acids Res. 2004, 32, W321W326.

[49] A. Ceroni, A. Passerini, A. Vullo, P. Frasconi, Nucleic Acids Res. 2006, 34, W177-W181.

[50] F. Marx, Appl. Microbiol. Biotechnol. 2004, 65, 133-142.

[51] Current Research, Technology and Education Topics in Applied Microbiology and Microbial Biotechnology (Ed.: A. Méndez-Vilas), Formatex Research Center, Badajoz, 2010.

Received: March 21, 2013 Revised: July 10, 2013 Published online: August 23, 2013 